\title{
EDITORIAL
}

\section{Mechanisms of interferon-alpha-induced depressive symptoms}

Wichers M C, M aes M. M echanisms of interferon-alpha-induced depressive symptoms.

A cta N europsychiatrica 2002: 14:103-105. (C) Blackwell M unksgaard 2002

\author{
M. C. Wichers, M. Maes
}

Department of Psychiatry and Neuropsychology, Maastricht

University, Maastricht, the Netherlands

Correspondence: M.C. Wichers, Department of Psychiatry and Neuropsychology, Maastricht University, PO BOX 616, 6200 MD Maastricht, the Netherlands. Tel. + 31-43-3871025;

Fax: + 31-43-3871026; http://users.skynet.be/crc.mh/

\section{Side-effects of interferon-alpha}

Several studies have found a high incidence of neuropsychiatric side effects during long-term interferon-alpha (IF $N \alpha$ ) therapy, including depressed mood, anxiety, loss of interest, slowness, severe fatigue, hypersomnia lethargy, poor appetite, irritability, short temper emotional lability, social withdrawal and lack of concentration (1). In a study from the $\mathrm{N}$ ational Institutes of $\mathrm{H}$ ealth (2) 10 of 58 patients (17\%) with chronic viral hepatitis treated with a 4-12-month course of recombinant IF $\alpha$ developed psychiatric side-effects. F urthermore, Bonaccorso et al. (1) found that of 30 patients, $40.7 \%$ suffered of major depression according to D SM -IV criteria after treatment with IF $\alpha$ for three months. Some studies even report that treatment with IF $\alpha$ may lead to suicidal thoughts and suicide attempts (3).

The mechanisms by which IF N $\alpha$ is able to influence brain function are not yet clear. Some mechanisms have been proposed and will be discussed below.

\section{Influence of IFN $\alpha$ on serotonin, cytokine network and HPA axis}

The brain is relatively isolated from the immune system due to the presence of the blood brain barrier (B B B) (4). H owever, it is thought that systemically administered IF N $\alpha$ is able to cross the BBB (5) and that it enters the brain through areas lack- ing the BBB, particularly the organum vasculosum lamina terminalis (6).

Serotonin $(5-\mathrm{H}$ T) plays an important role in mood regulation. $M$ ajor depression is accompanied by disturbances in the 5-H T metabolism (7). IF N $\alpha$ is able to affect the central serotonergic system. It up-regulates the transcription of the central 5-HT transporter, which enhances the reuptake of $5-\mathrm{HT}$ and causes a depletion of extracellular 5-HT (8). In addition, IF $\alpha$ affects the low-affinity 5-HTIA receptor sites (9) and it may be able to modulate 5-HT2 receptors (10). Furthermore, IFN $\alpha$ is able to modulate the 5-H T system through its effect on the enzyme indoleamine 2,3 dioxygenase (ID O), which induces the catabolism of tryptophan, the precursor of $5-\mathrm{HT}$, to kynurenine. Overstimulation of ID 0 leads to depletion of plasma concentrations of tryptophan and perhaps to reduced synthesis of 5-H T in the brain, as the latter depends on plasma availability of tryptophan (11). While IF N $\gamma$ directly affects ID 0 activity, I F N $\alpha$ has a weak direct effect and in addition an indirect effect through a $15-\mathrm{kD}$ a protein, which is a product of IF $\mathrm{N} \alpha$ treated monocytes and lymphocytes and which stimulates ID $O$ and IF N $\gamma$ production (12). Thus, IF $\mathrm{N} \alpha$ is able to influence the central $5-\mathrm{H}$ T system directly as well as by modulating peripheral tryptophan catabolism.

A nother mechanism by which IF $\mathrm{N} \alpha$ may be able to produce depressive symptoms is by modulating the hypothalamic-pituitary-adrenal (HPA) axis. The main driving force behind HPA activation is 
hypothalamic corticotropin-releasing factor (CR F ), which enhances the release of ACTH from the pituitary, which in turn stimulates the release of corticosteroids from the adrenal glands. O veractivity of the HPA axis, experimentally induced in animals by long-term central CRF-infusion, causes symptoms such as anxiety, anhedonia, anorexia, changes in sexual behavior and changes in sleeping pattern (13).

D epressed people also have an overactive HPA axis characterized by an increased number of ACTH and cortisol secretory pulses (14), elevated levels of CRF in the CSF (13), an increased number of CRF secreting neurons in limbic brain regions (15) and a reduced number of CR F binding sites in the frontal cortex secondary to increased CRF concentration (16). Administration of dexamethasone, a synthetic glucocorticoid, reveals, in depressed patients, a relative resistance to its suppressive effect on the activity of the H PA axis (17). Therefore, the hypothesis is postulated that negative feedback mechanisms through glucocorticoid receptors are impaired in depressives (17).

IF $N \alpha$ may affect the HPA axis by its effect on the cytokine network. It stimulates the production of other proinflammatory cytokines such as interleukin (IL )-1 and I L-6 (18). These cytokines are known to exert potent enhancing effects on the HPA axis by stimulating CRF, ACTH and the production of corticosteroids (19). A logical candidate pathway for IL-1 to influence the brain is via the vagus nerve (10th cranial nerve). $\mathrm{F}$ irst, the vagus innervates tissues known to participate in immune functions and branches of the vagus are often associated with lymph nodes that drain regions in which immune activation occurs. Secondly, the injection of IL-1 $\beta$ into the hepatoportal vein increases vagal electrical activity. In addition, subdiaphragmatic vagotomy blocks the neural, physiological and behavioral effects of IL $-1 \beta$ (20).

\section{Prevention of side-effects with antidepressants}

A ntidepressant pharmacotherapy may be useful to prevent the depressive side-effects of administration of IF N $\alpha$.

F irst, antidepressive agents exert an influence on the serotonergic system. A ntidepressant drugs may act via their long-term ability to modulate pre- and postsynaptic serotonergic function. Furthermore, tricyclic antidepressants such as clomipramine and imipramine, selective serotonin reuptake inhibitors (SSRIS) such as sertraline, heterocyclic antidepressants such as trazodone and 5-H TP, the direct precursor of 5-HT, are found to have a significant suppressive effect on the proinflammatory cytokine IF $\mathrm{N} \gamma$ and/or a stimulatory effect on IL-10 secretion, an anti-inflammatory cytokine whole blood stimulated with polyclonal activators (21). A nother study (22) showed that the antidepressants imipramine, clomipramine and citalopram caused an inhibition of IL-2 and IF N $\gamma$ release from activated $T$ cells after polyclonal activation and a similar inhibitory pattern was seen for IL $1 \beta$, TNF- $\alpha$ and IL- 6 release from monocytes. Thus, antidepressants may counteract the effects of IF N $\alpha$ on the cytokine network by its negative immunoregulatory effects.

F inally, antidepressant drugs such as desipramine, imipramine and amytriptyline (23) are able to decrease HPA activity. The fact that patients who do not respond to antidepressant treatment continue to have HPA dysregulation (24) supports a causal relationship between normalization of stress hormone regulation and clinical recovery. A ntidepressants may be able to down-regulate H PA activity by decreasing $\mathrm{CRH}$ gene expression in the paraventricular nucleus of the hypothalamus (25) and by increasing corticosteroid receptor sites in brain regions known to mediate the inhibitory effects of glucocorticoids on subsequent H PA activity, thereby increasing the feedback inhibition over the H PA axis (26).

In addition it has been shown that they are able to reduce IF N $\alpha$-induced depression. A dministration of paroxetine (27) and imipramine (28) have proven to be effective in alleviating IF $\mathrm{N} \alpha$-induced depressive symptoms in hepatitis $C$ patients. Thus, antidepressants might be useful to prevent the development of depression in IF N $\alpha$ therapy.

\section{References}

1. Bonaccorso S, M arino V, Biondi M , G Rimaldi F, I PpoliTI $F, M$ AES $M$. M ajor depression induced by interferonalpha in patients affected by hepatitis C virus. J Affect Disord 2000, in press.

2. Renault PF, Hoofnagle J H, Park $Y$ et al. Psychiatric complications of long-term interferon alfa therapy. A rch Intern M ed 1987;147:1577-1580.

3. Schafer M, M esser T, Wegner U, Schmid-Wendtner $M$ H, VolKenandt $M$. [Psychiatric side effects during adjuvant therapy with interferon-alpha in patients with malignant melanoma. Clinical evaluation as well as diagnostic and therapeutic possibilities]. H autarzt 1999;50:654-658.

4. D ARLING JJ, H OYLE N R, T HOMAS D GT. Self and non-self in the brain. Immunol Today 1981;2:176-181.

5. Pan W, B Anks WA, K astin A J. Permeability of the bloodbrain and blood-spinal cord barriers to interferons. J N euroimmunol 1997;76:105-111.

6. Shibata M, Blatteis CM . H uman recombinant tumor necrosis factor and interferon affect the activity of neurons in the organum vasculosum laminae terminalis. Brain Res 1991;562:323-326. 
7. M AES M, M ELTZER $H$. The serotonin hypothesis of major depression. In: B Loom F, K upfer D, eds. Psychopharmacology: the fourth generation of progress. N ew York: R aven Press, 1995, 933-944.

8. M orikawa $O$, Sakai $N$, O bara $H$, Saito $N$. Effects of interferon-alpha, interferon-gamma and CAMP on the transcriptional regulation of the serotonin transporter. E ur J Pharmacol 1998;349:317-324.

9. A be $S, H$ ori T, Suzuki T, B aba A, Shiraishi H, Y amamoто T. Effects of chronic administration of interferon alpha $A / D$ on serotonergic receptors in rat brain. N eurochem Res 1999;24:359-363.

10. Kugaya A, K agaya A, U chitomi $Y$, Yokota $N, Y$ amaWAKI S. Effect of interferon-alpha on DOI-induced wetdog shakes in rats. J N eural Transm 1996;103:947-955.

11. Heyes M P, Saito K, Crowley J $S$ et al. Quinolinic acid and kynurenine pathway metabolism in inflammatory and non-inflammatory neurological disease. Brain 1992;115: 1249-1273.

12. ReCht M, BoRden EC, K NIGHT E J r. A human $15-\mathrm{kD}$ a I F N -induced protein induces the secretion of I F N -gamma. J Immunol 1991;147:2617-2623.

13. N emeroff CB, W iderlov E, Bissette $G$ et al. Elevated concentrations of CSF corticotropin-releasing factor-like immunoreactivity in depressed patients. Science 1984;226: 1342-1344.

14. R ubin RT, Poland R E, L esser I M , W Inston R A , BlodgETT $A L$. N euroendocrine aspects of primary endogenous depression. I. Cortisol secretory dynamics in patients and matched controls. A rch General Psychiatry 1987;44:328336.

15. R Aadsheer F C, H oOgendiuk WJ, Stam FC, Tilders FJ, SWAAB DF. Increased numbers of corticotropin-releasing hormone expressing neurons in the hypothalamic paraventricular nucleus of depressed patients. N euroendocrinology 1994;60:436-444.

16. N emeroff CB, O wens MJ, Bissette G, A ndorn AC, STANLEY M. Reduced corticotropin releasing factor binding sites in the frontal cortex of suicide victims. A rch $G$ en Psychiatry 1988;45:577-579.

17. Carroll BJ. Clinical applications of the dexamethasone suppression test for endogenous depression. Pharmacopsychiatria 1982;15:19-25.
18. M Aes $M, C$ apuron $L, R$ aVAud $A$ et al. Lowered serum dipeptidyl peptidase IV activity is associated with depressive symptoms and cytokine production in cancer patients receiving interleukin-2-based immunotherapy. N europsychopharmacology 2001;24:130-140.

19. N aVarra P, T Sagarakis S, F aria M S, ReEs L H, Besser GM, G Rossman AB. Interleukins-1 and -6 stimulate the release of corticotropin-releasing hormone-41 from rat hypothalamus in vitro via the eicosanoid cyclooxygenase pathway. Endocrinology 1991;128:37-44.

20. M AIER SF, G OEHLer LE, F Leshner $M$, Watkins LR. The role of the vagus nerve in cytokine-to-brain communication. A nn NY A cad Sci 1998;840:289-300.

21. K ubera $M, K$ enis $G$, Bosmans $E$, Scharpe $S, M$ aes $M$. Effects of serotonin and serotonergic agonists and antagonists on the production of interferon-gamma and interleukin-10. N europsychopharmacology 2000;23:89-98.

22. $X_{\text {IA }} Z$, D EPIERRE J W, N ASSBERgER $L$. Tricyclic antidepressants inhibit IL -6, IL - 1 beta and TN F-alpha release in human blood monocytes and IL-2 and interferon-gamma in T cells. I mmunopharmacology 1996;34:27-37.

23. D uncan G E, K napp D J, C arson SW, B ReESE G R . D ifferential effects of chronic antidepressant treatment on swim stress- and fluoxetine-induced secretion of corticosterone and progesterone. J Pharmacol Exp Ther 1998;285:579587.

24. M aes M, De R uyter M, H obin P, Suy E. R epeated dexamethasone suppression test in depressed patients. J A ffect D isord 1986;11:165-172.

25. Brady LS, W hitfield H J J r, F Ox R J, G OLD PW, H ERKENHAM M. A ntidepressant drugs regulate corticotropin-releasing factor and tyrosine hydroxylase messenger R NAs in rat brain. J Clin Invest 1991;87:831-837.

26. R owe W, SteVerman $A$, Walker $M$ et al. A ntidepressants restore hypothalamic-pituitary-adrenal feedback function in aged, cognitively-impaired rats. Neurobiol A ging 1997; 18:527-533.

27. M usselman DL, L awson D H, G umnick J F et al. Paroxetine for the prevention of depression induced by high-dose interferon alfa. N Engl J M ed 2001;344:961-966.

28. G LEASON OC, Y ATES WR. F ive cases of interferon-alphainduced depression treated with antidepressant therapy. Psychosomatics 1999;40:510-512. 